\title{
Vitamin B12 - Do You Know Everything?
}

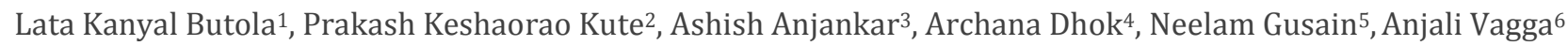

1, 2, 3, 4, 6 Department of Biochemistry, Jawaharlal Nehru Medical College, Datta Meghe Institute of Medical Sciences, Sawangi, Wardha, Maharashtra, India. ${ }^{5}$ Department.of Biochemistry, Al Falah School of Medical Sciences and Research Centre, Haryana. India.

\section{ABSTRACT}

\section{BACKGROUND}

The term Vitamin B12 is used as a generic descriptor for the cobalamins; cobalt containing compound possessing the corrin ring having the biological activity of vitamin. The active coenzyme forms of vitamin B12 are methylcobalamin and deoxyadenosylcobalamin. Dietary sources of vitamin B12 are of animal origin and include meat, eggs, milk, dairy products, fish and poultry. Vitamin B12 is absent in plant foods and humans obtain small amount of vitamin B12 from their intestinal flora. Vitamin B12 plays a crucial role in DNA synthesis, nucleoprotein, erythropoiesis, myelin synthesis, normal growth and cell reproduction and one carbon metabolism. Vitamin B12 deficiency may arise due to decreased dietary intake. Vitamin B12 helps in isomerization of methylmalonyl-CoA to succinyl-CoA by methylmalonyl-CoA mutase and also helps in conversion of homocysteine to methionine by methionine synthase. Dietary deficiency is seen in strict vegetarians, since vitamin found only in foods of animal origin or in microorganism. Deficiency of Vitamin B12 causes pernicious anaemia, megaloblastic anaemia, methylmalonic aciduria, Neuropathy and folate trap. The present review concludes that vitamin B12 deficiency affects a person's mental and physical health and it can cause severe, irreversible neurologic damage, disorientation, nerve damage, insomnia and many other diseases as mentioned in article. Adults should take $2.4 \mathrm{mcg}$ of vitamin B12, deficiency is mainly seen commonly in Vegetarian they have to add vegan sources of vitamin B12 to their diet which include fortified cereals, bread, nutritional yeast and plant milks. Early identification of vitamin B12 status should be preliminary screening step to reverse the damage caused by vitamin B12 deficiency which will helps in prevention of diseases.

\section{KEY WORDS}

Vitamin B12, Cardiovascular Diseases, Dementia, Metformin, Pregnancy, Diabetes Mellitus, Neuropathy, Osteoporosis, Ageing, Neural Tube Defects, Depression.
Corresponding Author: Lata Kanyal Butola. Department of Biochemistry, Jawaharalal Nehru Medical College, Datta Meghe Institute of Medical Sciences, Sawangi, Wardha, Maharashtra, India. E-mail: kanyallata1010@gmail.com

DOI: $10.14260 /$ jemds/2020/688

How to Cite This Article:

Butola LK, Kute PK, Anjankar A, et al. Vitamin B12 - do you know everything? J Evolution Med Dent Sci 2020;9(42):31393146, DOI: 10.14260/jemds/2020/688

Submission 18-05-2020,

Peer Review 08-09-2020,

Acceptance 15-09-2020,

Published 19-10-2020.

Copyright (C) 2020 Lata Kanyal Butola et al. This is an open access article distributed under Creative Commons Attribution License [Attribution 4.0 International (CC BY 4.0)] 


\section{BACKGROUND}

\section{A Brief History of B12}

The inceptive discovery of Vitamin B12 arose from the need to find the cause and cure for pernicious anaemia, first reported in 1849 by Thomas Addison. ${ }^{1}$ Treatment was discovered in 1926 when the consumption of lightly cooked liver led to the correction of anaemia and reduced the death rate, even though at that time proteins and iron in the liver were considered to be the curative factors. ${ }^{2}$ In late 1940s two groups announced the discovery of a new vitamin, which induced and sustained pernicious remission of anaemia ${ }^{3}$ In 1956 Dorothy Hodgkin an $\mathrm{X}$-ray crystallographer, discovered the structure of vitamin B12 and in 1973 Robert Woodward synthesized vitamin B124,5 William Castle summed up his work by showing the underlying cause of pernicious anaemia, which was due to lack of gastric intrinsic factor. ${ }^{6}$ B12 depletion characterized subclinical cobalamin deficiency has emerged as a major public health issue. Over the past 20 - 30 years, the prevalence of subclinical cobalamin deficiency has created interest in testing of B12 status. $^{7-9}$ The highest prevalence of irregular B12 status biomarkers is observed in people and populations with a low intake of food from animal sources and the elderly.

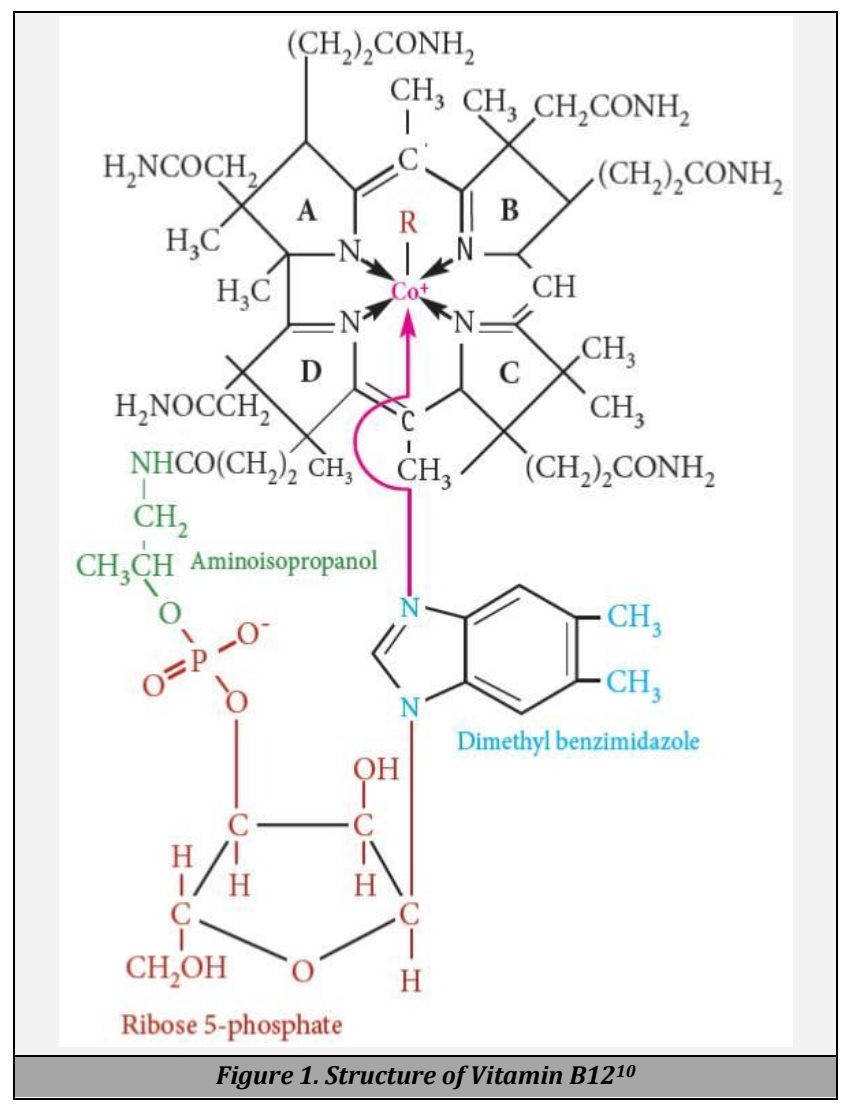

Vitamin B12 plays a key role in the synthesis of DNA,11 normal erythropoiesis, nucleoprotein, and myelin synthesis, cell replication, normal growth ${ }^{12}$ and one-carbon metabolism. ${ }^{13}$ Vitamin B12 exist in number of forms: cyano, methyl, deoxyadenosyl, aqua, nitro and hydroxy cobalamin. Vitamin B12 is synthesized in gastrointestinal tract by bacteria Lactobacillus reuteri, in animals and found in foods of animal origin, $, 14,15$ therefore vegetarians are at increased risk for B12 deficiency. Liver, meat, fish, eggs, milk, curd and cheese are good sources of vitamin B12.10,16

\section{Food Sources and Bioavailability of Vitamin B12}

Vitamin B12 is ultimately the product of microbial synthesis, because plants do not use vitamin, vitamin B12 is abundant in animal tissues and thus vitamin B12 can only be found in animal-derived foods, the main dietary sources are meat and meat products, dairy products, fish and shellfish and fortified ready to eat cereals. ${ }^{17}$

\begin{tabular}{|cc|}
\hline Animal Derived Food Rich in Vitamin B12 $(\boldsymbol{\mu g} / \mathbf{1 0 0} \mathbf{g})$ \\
Liver & $26-58 \mu \mathrm{g} / 100 \mathrm{~g}$ \\
Beef and lamb & $1-3 \mu \mathrm{g} / 100 \mathrm{~g}$ \\
Chicken & Trace $-1 \mu \mathrm{g} / 100 \mathrm{~g}$ \\
Eggs & $1-2.5 \mu \mathrm{g} / 100 \mathrm{~g}$ \\
Dairy Products & $0.3-2.4 \mu \mathrm{g} / 100 \mathrm{~g}$ \\
\hline Table 1. Vitamin B12 Derived Food \\
\hline
\end{tabular}

There are no bioactive forms of vitamin B12 from plant sources, naturally. Some plant foods contain added vitamin B12, while some contain vitamin B12 analogs, e.g. seaweed and mushrooms. 18

\begin{tabular}{|cc|}
\hline Age Group & RDA ( $\mathbf{~} c \mathrm{~g})$ \\
Adults & 2.0 \\
Children & 1.4 \\
Infants & 0.5 \\
Pregnant and Lactating Women & 2.6 \\
\hline Table 2. Recommended Dietary Allowance in Different Age Groups ${ }^{\mathbf{1 9}}$ \\
\hline
\end{tabular}

\section{Absorption of Vitamin B12}

Cobalamin absorption occurs through 2 mechanisms, one occurs passively through buccal, duodenal and ileal mucosa, and the other occurs through ileum by physiological mechanism and seems to be successful for small oral doses of cobalamin, mediated by gastric intrinsic factor. Two types of Vitamin B12 binders are found in human gastric juice, one with slow and one with rapid mobility in zone electrophoresis. The rapid component is $\mathrm{R}$ protein and slow component is IF. $\mathrm{R}$ proteins are mainly found in plasma, amniotic fluid, saliva, ascitic fluid, milk and granulocytes. Dietary cobalamin released by enzymes in the stomach, duodenum, and jejunum from protein complexes ${ }^{20}$ and binds to a glycoprotein- $\mathrm{R}$ protein secreted by salivary gland belonging to the family of cobalamin-binding protein known as haptocorrins. ${ }^{11,20}$

The $\mathrm{R}$ protein is hydroxylated in the duodenum in the presence of alkaline medium and pancreatic proteases to release vitamin $\mathrm{B} 12$, which later binds a $50 \mathrm{kDa}$ molecular weight glycoprotein with intrinsic factor.9,11 It (chromosome gene 11q13) is produced in fundus and stomach parietal gastric cells. Vitamin B12-IF passes to the ileum, where it attaches to the enterocyte microvillus membrane at a specific receptor (Cubilin). Cubilin is also present in the yolk sac and epithelium of the renal tubules. Cubilin appears to be trafficking via amnion less, an endocytic receptor protein that guides cubilin sub-localization and endocytosis with its ligand vitamin B12-IF complex entering the ileal cell, where it is destroyed. Vitamin B12 enters the circulation about 2 - 3 hours and appears in portal blood attached to transcobalamin $2.14,20$

\section{Transport}

Transcobalamin 1 (TC-1) and transcobalamin 2 (TC-2) transports vitamin B12. TC- 1 is derived from specific granules in neutrophils, also known as haptocorrin and encoded by TCN 1 gene. TC-1 does not facilitate the entry of cobalamin into tissues. The removal of TC- 1 from plasma includes the 
glycoprotein receptors in liver cells, it also plays role in transport of cobalamin analogues to the liver for excretion in bile and TC-2, gene is present on chromosome 22q11q13.1 with a molecular weight of $43 \mathrm{kDa}^{1}$ synthesized by liver, macrophage, ileum and vascular endothelium. ${ }^{21} 80 \%$ of vitamin is transported in circulation as inactive TC- 1 and $20 \%$ vitamin is transported in circulation in active form called
Transcobalamin II (TC II). The TC II complex also alluded to as holo TC II is taken actively by the liver, bone marrow, and other vital cells. ${ }^{11,14}$

Liver can store about 4 - $5 \mathrm{mg}$, an amount sufficient to meet the body requirements of B12 for 4 - 5 years, and the clinical features of deficiency become apparent by 5 years.
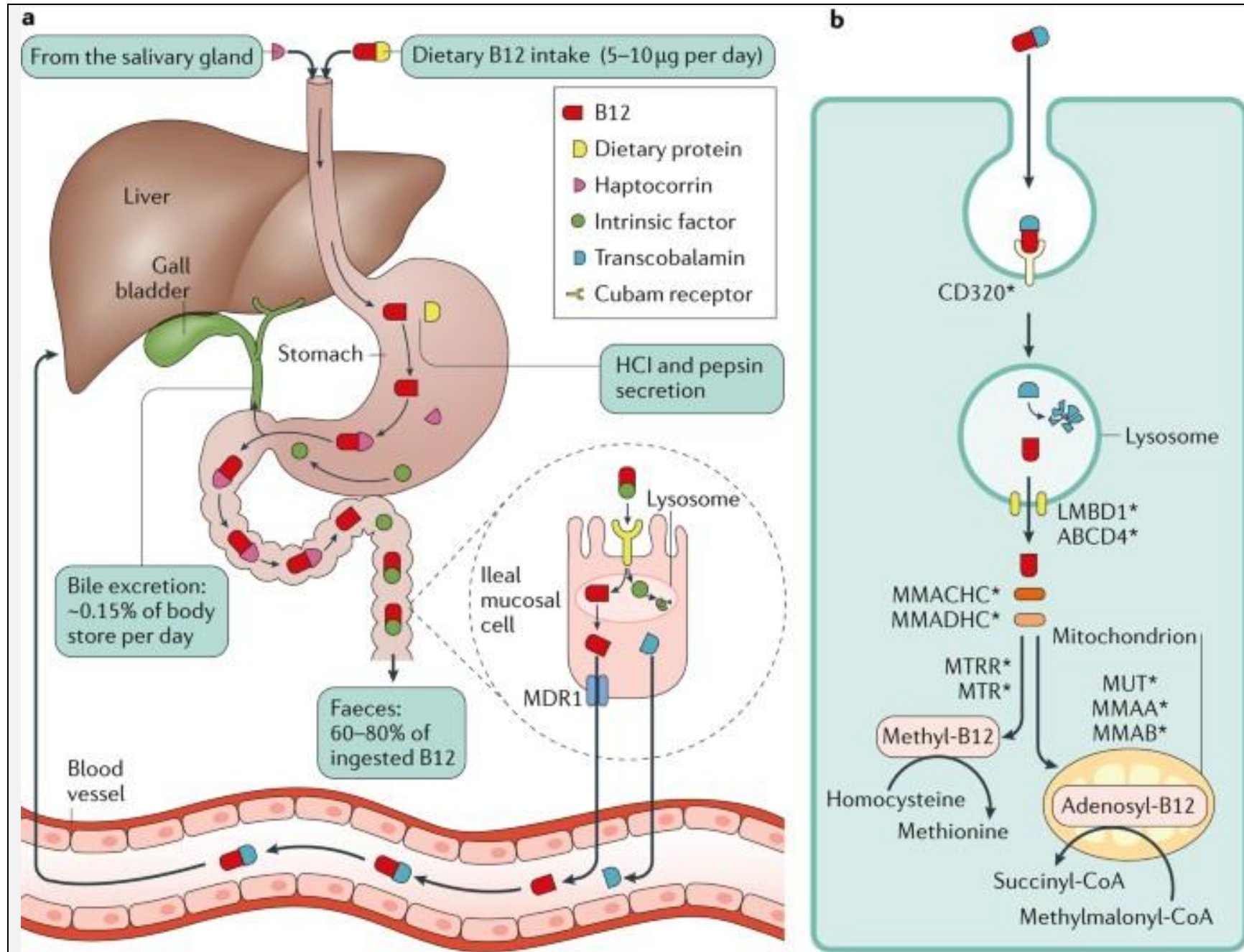

Nature Reviews | Disease Primers

\section{Biochemical Role of Vitamin B12}

Vitamin B12 acts as a methyl donor to membrane phospholipids, neurotransmitters, amines, DNA and RNA, and myelin-based proteins. ${ }^{10,23}$ The deficiency of vitamin B12 causes myelin damage by increasing myelinotoxic growth factors and cytokines. It also helps to transform methyl tetrahydrofolate, the circulating form of folate to tetrahydrofolate, the active form of folate that helps in the synthesis of nucleotides and DNA. ${ }^{20,24}$

\section{Biochemical Assessment of Vitamin B12 Status}

Homocysteine and methylmalonic acid known as markers of Vitamin B12, assessment of these biomarkers demonstrated the presence of a subclinical disorder, whose implications are still being elucidated. The main cobalamin metabolic predictor is methylmalonic acid, and homocysteine is increased in vitamin B12 deficiency along with Vitamin B6 and folate deficiencies. Physiological or environmental factors may confound certain biomarkers, homocysteine levels are elevated in renal dysfunction and MMA levels are elevated in renal insufficiency, typically in older persons. ${ }^{25,26}$

\section{VITAMIN B12 DEFICIENCY}

\section{Causes}

- Pernicious anaemia.

- Gastric disease.

- Chronic atrophic gastritis.

- Pancreatic disease or pancreatectomy.

- Ileal resection. 


\section{Adenosyl-Cobalamin}

L-methylmalonyl-CoA

Succinyl-CoA

\section{Methyl-cobalamin Methionine Synthase}
5-Methyl-tetrahydrofolate
Tetrahydrofolate
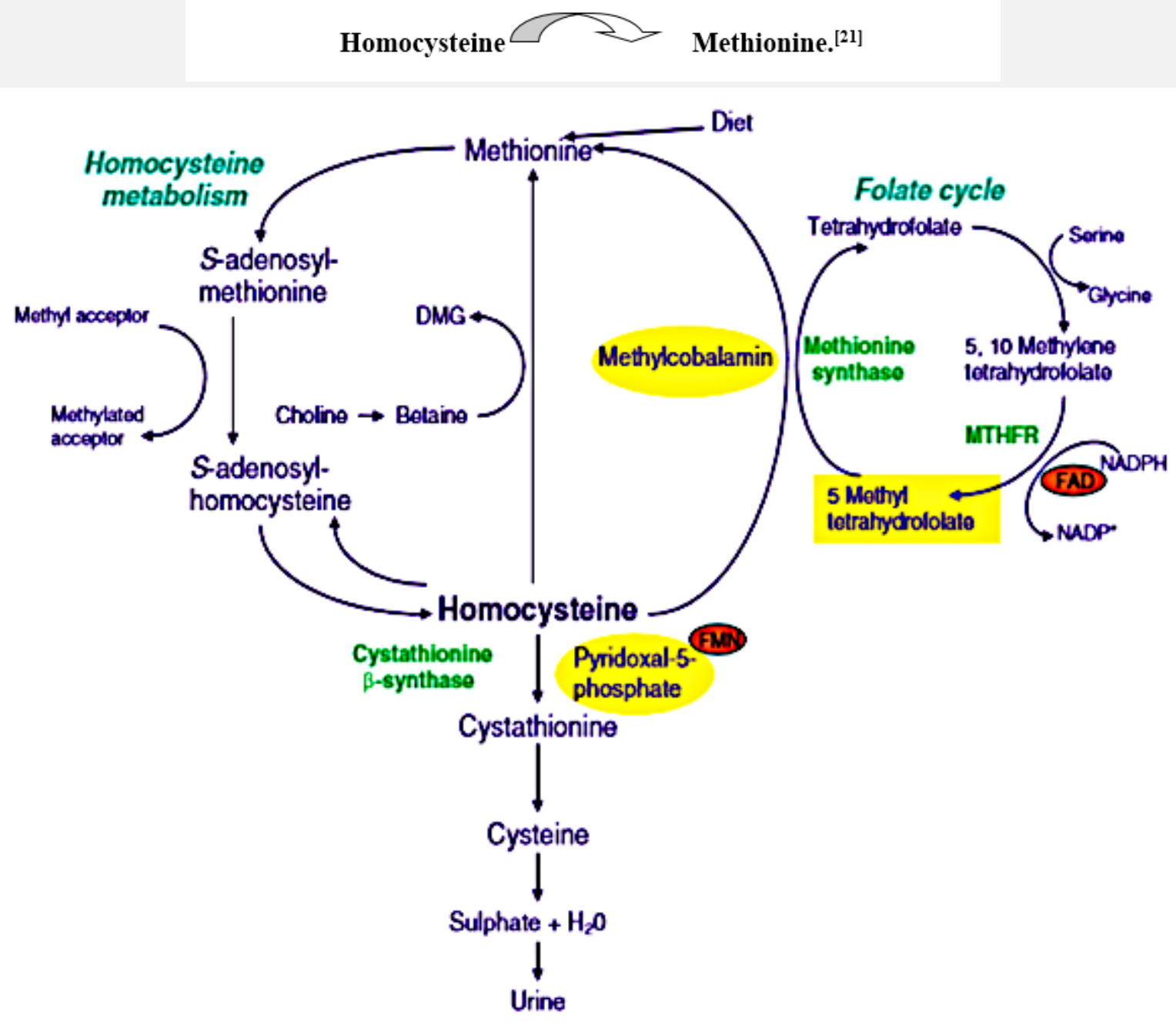

Figure 3. Metabolic Pathway that Includes Vitamin B12 Re-Methylation of Homocysteine to Methionine and Folate Recycling

- Bacterial overgrowth.

- Dietary factors like: General malnutrition, vegetarian or vegan diet, and chronic alcoholism.

- Inherited disorders.

- Miscellaneous: Nitrous oxide anaesthesia and HIV infection. ${ }^{27}$

\section{Vitamin B12 and Neural Tube Defects}

Neural tube defects (NTDs) are central nervous system congenital abnormalities (CAs). Alongside congenital heart abnormalities (CHAs) and urinary system disorders, they are the most common birth defects. The neurulation is a significant phase in brain development, involving the creation of the first well-defined neural tunnel. The neural tube forms in the third week of gestation $\left(20-28\right.$ days). ${ }^{28,29}$ Twenty percent of the foetuses die in utero (therapeutic abortions or stillbirths). Many people die in the first week of existence, with only 10 percent of people dying in the first year. Many living after this time would usually have poor healthy lives and frequent interventions in medicine, surgery, and physiotherapy. ${ }^{30}$ Vitamin B12-dependent synthase of methionine is a checkpoint reaction in which folate molecules are introduced into the cells, since folate exists primarily as circulating methyl folate. Folate cofactors will then assist in the transition of other one-carbon groups to nucleotide molecules intended for DNA synthesis or other molecular products after 


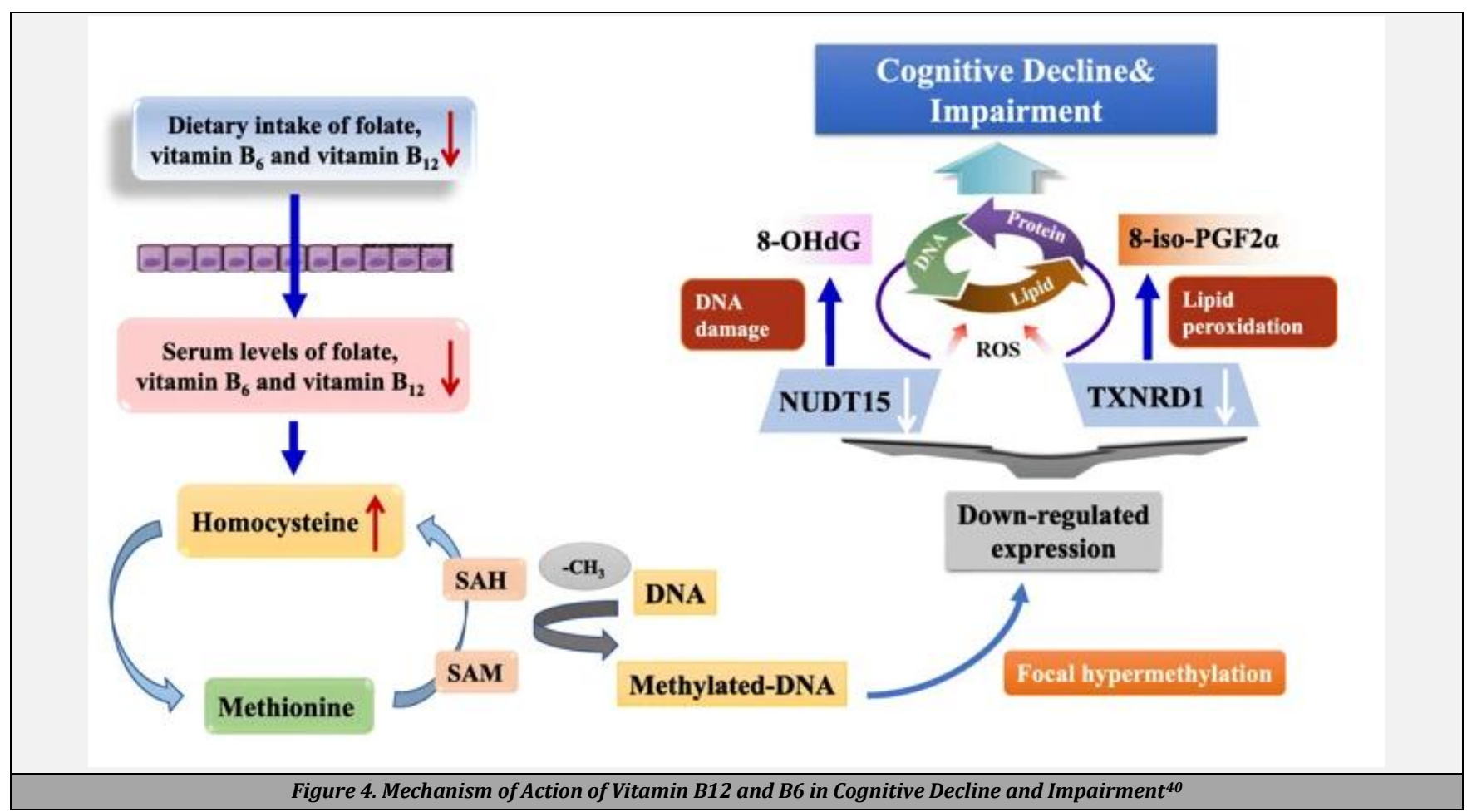

releasing the methyl group into homocysteine through the methionine synthase reaction within the cell. ${ }^{31}$ Impaired methionine synthase contribute to the cellular accumulation of the methyl folate substratum, which has no alternative metabolic outlet. The cell is thus functionally deficient in folates, and the synthesis of folate-dependent DNA is impaired, leading to megaloblastic anaemia. The cell is thus functionally deficient in folates, and the synthesis of folate-dependent DNA is impaired, leading to the classic megaloblastic anaemia that characterizes folate and B12 deficiency. It is significant to mention that folic acid bypass vitamin B12 dependent methionine synthase to enter the cellular folate pool and resume folate functions in relation to DNA synthesis, but it cannot correspond to supplying methyl group for the abovementioned methylation functions. Lower levels of serum folate and vitamin B12 are linked with an increased incidence of developmental anomalies, such as neural tube defect. ${ }^{32}$ Folate and Vitamin B12 were considered important in the occurrence and reoccurrence of NTD and essential factors for range of metabolic pathways in cells involving the transfer of one carbon units and methylation reactions..$^{33}$ Vitamin deficiency and elevated levels of homocysteine plays a possible role in early pregnancy.

\section{Vitamin B12 and Cardiovascular Diseases}

Coronary artery disease (CAD) was caused primarily by endothelial dysfunctional atherosclerosis ${ }^{34,35}$ and is significantly harmful to the stable condition of people in both developed and developing countries. Folic acid and vitamin B12 are instrumental in controlling the metabolic process of Hcy (Homocysteine). Conversely, HHcy (Hyperhomocysteinaemia) may result in a shortage of folic acid and vitamin B12. Deficiency of vitamin B12 and HHcy are related to risk factors for cardiovascular disease in patients with CAD.

\section{Vitamin B12 and Cognitive Decline}

An elevated level of Hcy as a neurotoxin was also shown to affect the redox signalling pathways in neurons through the generation of reactive oxygen species (ROS) and a decrease in endogenous antioxidants. ${ }^{36}$ If patterns of DNA methylation in redox-related genes can modulate cognitive impairment caused by vitamin B12 deficiency and hyperhomocysteinaemia is therefore of interest, low levels of vitamin B12 can cause serious cognitive dysfunction. ${ }^{37}$ Increased homocysteine levels are related to cardiovascular disease, stroke and Alzheimer's disease and a low level of vitamin B12 and increased concentration of homocysteine causes silent injury to brain due to oxidative stress, which results in calcium inflow and apoptosis. ${ }^{38,39}$

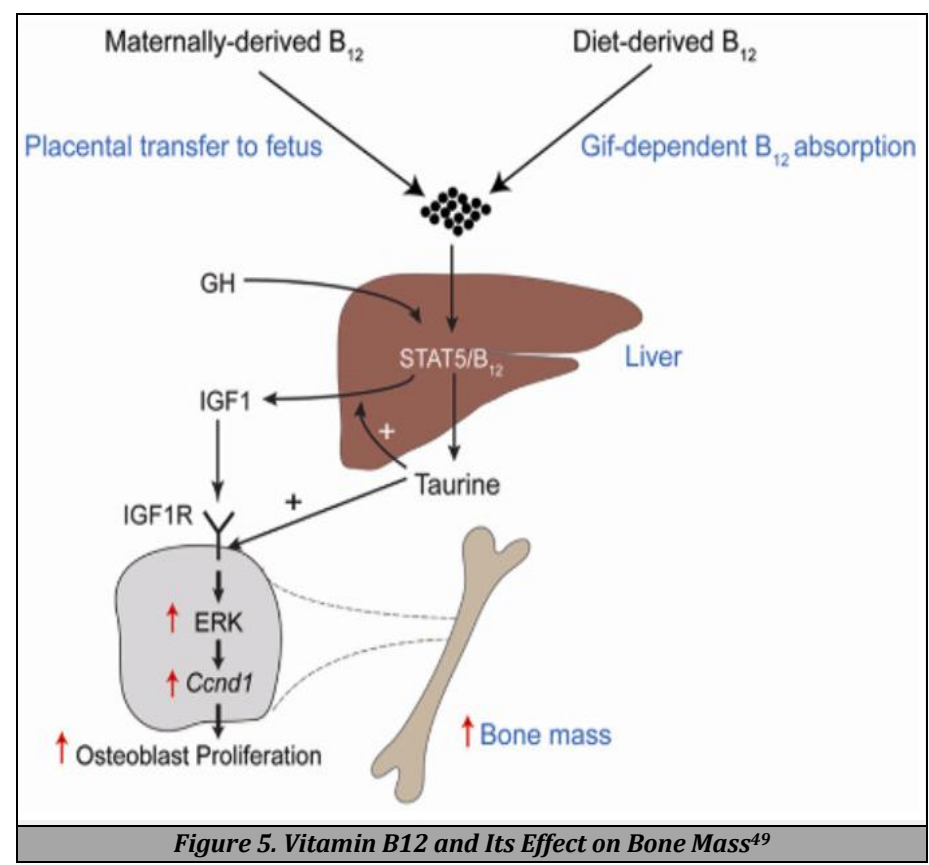




\section{Vitamin B12 and Osteoporosis}

Low vitamin B12 levels increase risk of decreased mineral density and fractures in the bones. Low vitamin B12 levels in conjunction with a deficiency in folate and vitamin B6 are closely related to the Hcy metabolism. Contrasting findings have been shown in the combination with hyperhomocysteinaemia with lower bone mineral density (BMD) and risk of osteoporotic fractures. ${ }^{41,42}$ Hyperhomocysteinaemia is associated with increased bone remodelling markers and thus an increased risk of fracture. Thus, hyperhomocysteinaemia caused by vitamin B12 deficiency as well as folate can be considered as potential risk factors for osteoporosis due to these micronutrient deficiencies. Homocysteine reduces bone blood flow, increases metalloproteinase matrix, ${ }^{43}$ and interferes with cross-linking of collagen. ${ }^{44,45}$ Collagen cross-linking provides strength and stability to the bone matrix collagen network. Cathepsin-K (CathK) is expressed mainly in osteoclasts and is necessary for bone resorption. ${ }^{46}$ High CathK levels are seen in osteoporotic women. ${ }^{47,48}$

\section{Vitamin B12 and Ageing}

At present, vitamin B12 deficiency is considered to be normal and its prevalence increases with age. Depending on the diagnostic criteria used, 50 it is estimated to affect 5 - 40 percent of the age group. Vitamin B12 was linked to age related macular degeneration growth and frailty risk, both leading causes of elderly disability. AMD is the leading cause of loss in vision in older people. Host factors include high age, hypertension, family history, obesity, sunlight sensitivity, smoking and hypercholesterolemia. Frailty is characterized by muscle waste, depleted strength, often with weight loss with or without reduced food intake. 51

\section{Vitamin B12 and Diabetes Mellitus}

Type 2 diabetes mellitus is a multifactorial disease linked to energy metabolism mainly carbohydrates and fats and has macro vascular and micro vascular complications. ${ }^{52} \mathrm{RBC}$ of vitamin B12 deficient patients contains dwindled glutathione or enzymes, which were essential for degradation of glucose to ribose and further leads to elevation of coenzyme $\mathrm{A}$ in the liver. 53 The increased fatty acid metabolism leads to increased intra-mitochondrial acetyl Coenzyme A; which inhibits pyruvate dehydrogenase resulting in inhibition of phosphofructokinase the key enzyme in glycolysis. Hyperglycaemia develops advanced glycation end products (AGE). AGE contributes to pathogenesis of demyelination by macrophages. Schwann cell abnormalities include both reactive changes (accumulation of lipid droplets, glycogen and Pi granules of Reich) and degenerative changes (effacement of cristae, mitochondrial enlargement, degeneration of abaxonal and adaxonal cytosol and organelles) leading initially to demyelination with development of neuropathy, axonal degeneration and inducing loss of nerve fibre. ${ }^{54}$ Vitamin B12 is important to monitor in patients with type 2 diabetes mellitus as the declining vitamin B12 levels hampers the maintenance of enzyme system essential for utilization of carbohydrates and fats. ${ }^{55}$

\section{Vitamin B12 and Metformin}

Metformin is used for the treatment of diabetes, it affects the calcium dependent ileal cell membrane receptors needed for uptake of B12 intrinsic factor and reduces serum vitamin B12 absorption up to $30 \% .^{56}$ Metformin-induced vitamin B12 deficiency in T2DM patients, which involves alteration in small intestine motility, bacterial flora, competitive inhibition and inactivation of vitamin B12 absorption, alteration in intrinsic factors levels, interactions with endocytic cubilin receptors or the effect of calcium on cell membrane, was suggested to play a role as a biguanide group that is protonated and prevents calcium dependent absorption which was reserved with calcium supplementation. ${ }^{57}$

\section{Depression and Vitamin B12}

Vitamin B12 plays a significant role in development of the neurology and DNA synthesis. Its deficiency has to do with hematology, neurology and psychological symptoms, the latter involving irritability, changes in personality, depression, dementia, and rarely psychosis. The linkages between deficiency of vitamin and depression have been established in recent literature. High serum B12 levels are blessed with improved treatment response, high levels of homocysteine typical of folate / B12 deficiency, and poor response to antidepressant therapy are associated with those with depression. ${ }^{58}$ Hyperhomocysteinaemia can have direct effects on depression-implied neurotransmitters. ${ }^{59}$

\section{CONCLUSIONS}

The present review concludes that vitamin B12 deficiency affects a person's physical and mental health and it can cause severe, irreversible neurologic damage, disorientation, nerve damage, insomnia and many other diseases as mentioned in the article. Adults should take adequate amount of vitamin B12 and deficiency is mainly seen commonly in vegetarians and they have to add vegetarian and vegan sources of Vitamin B12 to their diet. As vitamin B12 plays a major role in nervous system; its deficiency may cause tingling in the hands or feet; sometimes peripheral nerve damage leads to movement problems; it also causes megaloblastic anaemia, shortness of breath, fast heart rate, cognitive impairment, irritability or depression, and pernicious anaemia. So, people who are having vitamin deficiency should take B12 supplements in the form of oral or sublingual tablets, or injections, add fish and red meat in diet, and add variety of fruits and vegetables in diet. So, early identification of vitamin B12 status should be preliminary screening step to mitigate the damage caused by vitamin B12 deficiency which will help in prevention of diseases and life threatening complications.

Financial or other competing interests: None.

Disclosure forms provided by the authors are available with the full text of this article at jemds.com. 


\section{REFERENCES}

[1] Addison T. Anaemia-disease of the suprarenal capsules. Medical Gazette 1849;43:517-18.

[2] Minot GR, Murphy WP. Treatment of pernicious anaemia by a special diet. 1926. Yale J Biol Med 2001;74(5):34153.

[3] Rickes EL, Brink NG, Koniuszy FR, et al. Crystalline vitamin B12. Science 1948;107(2781):396-7.

[4] Hodgkin DC, Kamper J, Mackay M, et al. Structure of vitamin B12. Nature 1956;178(4524):64-6.

[5] Woodward RB. The total synthesis of vitamin B 12. Pure Appl Chem 1973;33(1):145-77.

[6] Castle WB. Observations of the etiologic relationship of achylia gastrica to pernicious anaemia: I. The effect of administration to patients with pernicious anaemia of the contents of the normal human stomach recovered after the ingestion of beef muscle. Am J Med Sci 1929;178:748.

[7] Carmel R. Biomarkers of cobalamin (vitamin B-12) status in the epidemiologic setting: a critical overview of context, applications, and performance characteristics of cobalamin, methylmalonic acid, and holotranscobalamin II. Am J Clin Nutr 2011;94(1):348S-58S.

[8] Fedosov SN, Brito A, Miller JW, et al. Combined indicator of vitamin B12 status: modification for missing biomarkers and folate status and recommendations for revised cut-points. Clin Chem Lab Med 2015;53(8):121525.

[9] Burtis CA, Ashwood ER, Bruns DE. Diabetes mellitus. In: Tietz textbook of clinical chemistry and molecular diagnosis. $5^{\text {th }}$ edn. Sunders/Elsevier 2012:1415, 1441-2.

[10] Rafi MD. Textbook of biochemistry for medical students. $2^{\text {nd }}$ edn. Hyderabad: University Press (India) Private Limited 2014: p. 170.

[11] Kibirige D, Mwebaze R. Vitamin B12 deficiency among patients with diabetes mellitus: is routine screening and supplementation justified? J Diabetes Metab Disord 2013;12(1):17.

[12] Siddiqua TJ, Allen LH, Raqib R, et al. Vitamin B12 deficiency in pregnancy and lactation: Is there a need for pre and post-natal supplementation? J Nutr Disorders Ther 2014;4(2):142.

[13] Chahal JS, Raina SK, Sharma KK, et al. How common is Vitamin B12 deficiency-A report on deficiency among healthy adults from a medical college in rural area of North-West India. Int J Nutr Pharmacol Neurol Dis 2014;4(4):241-5.

[14] 0'Leary F, Samman S. Vitamin B12 in health and disease. Nutrients 2010;2(3):299-316.

[15] Taranto MP, Vera JL, Hugenholtz J, et al. Lactobacillus reuteri CRL1098 produces cobalamin. Journal of Bacteriology 2003;185(18):5643-7.

[16] Akuri SR. Significance of Vitamin B12 deficiency in patients with type 2 diabetes mellitus. Int J Pharm Bio Sci 2014;5(3):647-52.

[17] Heyssel RM, Bozian RC, Darby WJ, et al. Vitamin B12 turnover in man. The assimilation of vitamin B12 from natural foodstuff by man and estimates of minimal daily requirements. Am J Clin Nutr 1966;18(3):176-84.

[18] Stabler SP, Allen RH. Vitamin B12 deficiency as a worldwide problem. Annu Rev Nutr 2004;24:299-326.
[19] Patel HL, Gor SK, Shah AM, Dhanani J. Prevalence of vitamin B12 deficiency in highersocio-economical class of bhuj-kutch. Journal of Pharmacy 2012;2(5):1-3.

[20] Kasper D, Fauci A, Hauser S, et al. Diabetes mellitus. In: Harrison's principles of internal medicine. $19^{\text {th }}$ edn. New York: McGraw-Hill Education 2015: p. 2422, 2399.

[21] Delva MD. Vitamin B12 replacement. To B12 or not to B12? Can Fam Physician 1997;43:917-22.

[22] Green R, Allen LH, Bjørke-Monsen AL, et al. Vitamin B12 deficiency. Nat Rev Dis Primers 2017;3:17040.

[23] Ahmed S, Rohman S. Study of serum Vitamin B12 and its correlation with Lipid profile in type 2 diabetes mellitus. Indian J Basic Appl Med Res 2016;5(4):92-103.

[24] Lachner C, Steinle NI, Regenold WT. The neuropsychiatry of vitamin B12 deficiency in elderly patients. J Neuropsychiatry Clin Neurosci 2012;24(1):5-15.

[25] Carmel R. Mild transcobalamin I (haptocorrin) deficiency and low serum cobalamin concentrations. Clin Chem 2003;49(8):1367-74

[26] Carmel R, Green R, Rosenblatt DS, et al. Update on cobalamin, folate, and homocysteine. Hematology Am Soc Hematol Educ Program 2003:62-81.

[27] Carmel R. Prevalence of undiagnosed pernicious anaemia in the elderly. Arch Intern Med 1996;156(10):1097-100.

[28] Sadler TW. Langman's medical embryology. $12^{\text {th }}$ edn. Philadelphia: Lippincott Williams \& Wilkins 2012.

[29] Stiles J, Jernigan T. The basics of brain development. Neuropsychol Rev 2010;20(4):327-48.

[30] Czeizel AE, Dudás I, Paput L, et al. Prevention of neuraltube defects with periconceptional folic acid, methylfolate, or multivitamins? Ann Nutr Metab 2011;58(4):263-71.

[31] Molloy AM, Pangilinan F, Brody LC. Genetic risk factors for folate-responsive neural tube defects. Ann Rev Nutr 2017;37:269-91.

[32] Czeizel AE, Dudas I. Prevention of the first occurrence of neural-tube defect by periconceptional vitamin supplementation. N Engl J Med 1992;327(26):1832-5.

[33] Blom HJ, Shaw GM, den Heijer M, et al. Neural tube defects and folate: case far from closed. Nat Rev Neurosci 2006;7(9):724-31.

[34] Choi BJ, Matsuo Y, Aoki T, et al. Coronary endothelial dysfunction is associated with inflammation and vasa vasorum proliferation in patients with early atherosclerosis. Arterioscler Thromb Vasc Biol 2014;34(11):2473-7.

[35] Ruggiero D, Paolillo S, Ratta GD, et al. Endothelial function as a marker of pre-clinical atherosclerosis: assessment techniques and clinical implications. Monaldi Arch Chest Dis 2013;80(3):106-10.

[36] Sanchez-Espinosa MP, Atienza M, Cantero JL. Sleep mediates the association between homocysteine and oxidative status in mild cognitive impairment. Sci Rep 2017;7(1):7719.

[37] Selhub J, Bagley LC, Miller J, et al. B vitamins, homocysteine, and neurocognitive function in the elderly. Am J Clin Nutr 2000;71(2):614-20.

[38] Sudha S, Alexa B, Jacob S, et al. Plasma homocysteine as a risk factor for dementia and Alzheimer's disease. $\mathrm{N}$ Engl J Med 2002;346(7):476-83.

[39] Boushey CJ, Beresford SA, Omenn GS, et al. A quantitative assessment of plasma homocysteine as a risk factor for 
vascular disease. Probable benefits of increasing folic acid intakes. JAMA 1995;274(13):1049-57.

[40] An Y, Feng L, Zhang X, et al. Dietary intakes and biomarker patterns of folate, vitamin B 6, and vitamin B 12 can be associated with cognitive impairment by hypermethylation of redox-related genes NUDT15 and TXNRD1. Clin Epigenetics 2019;11(1):139.

[41] Bahtiri E, Islami $\mathrm{H}$, Rexhepi $\mathrm{S}$, et al. Relationship of homocysteine levels with lumbar spine and femur neck BMD in postmenopausal women. Acta Reumatol Port 2015;40(4):355-62.

[42] Gerdhem P, Ivaska KK, Isaksson A, et al. Associations between homocysteine, bone turnover, BMD, mortality, and fracture risk in elderly women. J Bone Miner Res 2007;22(1):127-34.

[43] Lubec B, Fang-Kircher S, Lubec T, et al. Evidence for McKusick's hypothesis of deficient collagen cross-linking in patients with homocystinuria. Biochim Biophys Acta 1996;1315(3):159-62.

[44] Jahn O, Wex T, Klose S, et al. Cathepsin K in treatment monitoring following intravenous zoledronic acid. Biomed Rep 2014;2(6):915-7.

[45] Holzer G, Noske H, Lang T, et al. Soluble cathepsin K: a novel marker for the prediction of nontraumatic fractures? J Lab Clin Med 2005;146(1):13-7.

[46] Muñoz-Torres M, Reyes-García R, Mezquita-Raya P, et al. Serum cathepsin $\mathrm{K}$ as a marker of bone metabolism in postmenopausal women treated with alendronate. Maturitas 2009;64(3):188-92.

[47] Yadav VK. Vitamin B12 as a regulator of bone health. Current science 2018;114(8):1632.

[48] Baik HW, Russell RM. Vitamin B12 deficiency in the elderly. Annu Rev Nutr 1999;19:357-77.

[49] Carmel R. Current concepts in cobalamin deficiency. Annu Rev Med 2000;51:357-75.

[50] Bjorkegren K, Svardsudd K. Serum cobalamin, folate, methylmalonic acid and total homocysteine as vitamin
B12 and folate tissue deficiency markers amongst elderly Swedes-a population-based study. J Intern Med 2001;249(5):423-32.

[51] Veeramalla V, Madas S. Correlation of glycated hemoglobin and iron deficiency anaemia among diabetic and non diabetic patients. Int J Curr Microbiol App Sci 2017;6(12):2669-75.

[52] Lotake DV, Barsode DS. Relation of vitamins in diabetes melliatus. International Journal of Innovative Research in Medical Science 2018;3(4):1925-8.

[53] Ralston SH, Penman ID, Strachan MWJ, et al. Hepatology. In: Davidson's principles and practice of medicine. $23^{\text {rd }}$ edn. Elsevier 2018:882-3.

[54] Madhura TK, Kanyal L, Mujawar A. Effect of glycemic control on vitamin B12 status in type 2 diabetes mellitus. Indian Journal of Basic and Applied Medical Research 2019;1(9):7-17.

[55] Rusher DR, Pawlak R. A review of 89 published case studies of vitamin B12 deficiency. J Hum Nutr Food Sci 2013;1(2):1008.

[56] Kibirige D, Mwebaze R. Vitamin B12 deficiency among patients with diabetes mellitus: is routine screening and supplementation justified? J Diabetes Metab Disord 2013;12(1):17.

[57] Kanyal L, Madhura TK. Status of vitamin B12 in type 2 diabetes mellitus patients taking metformin based oral hypoglycemic agent-a cross sectional study. Indian J Basic Appl Med Res 2019;1(9):18-26.

[58] Hintikka J, Tolmunen T, Tanskanen A, et al. High vitamin B12 level and good treatment outcome may be associated in major depressive disorder. BMC Psychiatry 2003;3:17.

[59] Bottiglieri T, Laundy M, Crellin R, et al. Homocysteine, folate, methylation, and monoamine metabolism in depression. J Neurol Neurosurg Psychiatry 2000;69(2):228-32. 